vol. 1, 2010

\title{
USING ART AS A MEDIUM TO ENHANCE SOCIAL RESPONSIBILITY AND CITIZENSHIP
}

\author{
Elmarie Costandius \\ Stellenbosch University, South Africa
}

\begin{abstract}
The aim of this research is to consider the impact of a Service-Learning module aiming at enhancing social responsibility and citizenship by using art as a medium for learning and reflection. It involves an explicit and designed programme that includes Socratic discussions and self-reflection projects through art. Action research was used as a methodology, ensuring that the whole class and the researcher were involved in the research process. The results of the project demonstrated that art is an effective medium to address sensitive issues because it functions on a symbolic and metaphorical level. Art that uses metaphors involves participants both consciously and sub-consciously and encourages possibilities for a diversity of interpretations.
\end{abstract}

Key words: responsible citizenship, service-learning, self-reflection, art and design

\section{Introduction}

This research aims to consider the impact of a Service-Learning module that envisions enhancing social responsibility and citizenship by using art as a medium for learning and reflection. Action research was used as a method for the module, and the psychoanalytic learning perspective (Fenwick, 2001) was used as a framework for teaching and learning in the module.

Service-learning is understood as an interaction that renders a service or addresses a need in communities outside the academic environment. Service-learning at Stellenbosch University (SU) is envisioned as a transformative pedagogy that is community-oriented and learner-centred. The aim of service-learning is to create an environment within which knowledge can be discovered, shared and applied to the benefit of the community. Bringle and Hatcher's (1999) formulation of service-learning is employed at Stellenbosch University. Service-learning is regarded as a curriculum-based, credit-bearing and carefully structured educational experience (Stellenbosch University, service-learning, 2011). Service-learning is integrated in the curriculum in credit-bearing modules with the aim to enhance the teaching and learning process. Service-learning, therefore, could create a space where interaction can take place and social responsibility and citizenship could be enhanced.

The importance of service-learning is also underlined by the South African Department of Education in the Education White Paper of 1997. The mission statement of the SU Visual Arts department emphasizes the importance of respect for diversity and knowledge applied for the benefit of the community. The Visual Arts course general 
outcomes state, for instance, that by the end of the module a student will have an understanding of the diversity of historical and cultural developments, of the world as a set of related systems and of the importance of promoting the preservation of indigenous knowledge in the world. But the questions remain: How do we reach these course outcomes in this module? How do we practically foster social responsibility and citizenship?

The author lives in an eco village that includes people from different income groups, races and cultures. The major issues in the village are not ecological because it is very clear to everyone that we follow certain regulations to realize an ecological way to build and live. It is the social side of the co-existence that is not all that clear, far more complex and not often spoken about. It is the subtle nuances in conversations, subconscious stereotyping or ingrained perceptions, inherited or indirect knowledge (Jansen, 2009) that need to be addressed for a postcolonial and post-apartheid society to heal and grow. A concrete effort and a structured module are needed to address issues of social responsibility and citizenship. Art can be used as a medium to enhance the process of becoming a more socially responsible citizen.

According to Beagan (2003), a socially responsible individual is a person who takes part in activities that contribute to the happiness, health and prosperity of the whole community and its members. Nussbaum (2002) refers to relevant abilities such as the ability to criticize your own traditions, showing mutual respect for other opinions, thinking as a citizen of the world and not only locally and imagining yourself in the shoes of others what she (Beagan, 2003) calls the "narrative imagination". Weinstein (2004) emphasizes teaching to see the Other, but also to be the Other, in other words, reflecting in the voice of the Other. Weinstein (2004) highlights the value of biographical writing where reality is stated clearly, which is more valuable than imaginative writings in novels. Weinstein (2004) also stresses the teaching of difference and not social cohesion or social harmony because cohesion assumes that there are no major differences, which leaves little room for a situation where there are differences and little social cohesion. Accepting difference needs a more complex emotional response than believing or assuming that there is social harmony.

\section{Research methodology}

Students approached their own involvement with communities as a participatory action research (PAR) project. The method of PAR was employed since it involves the participants as an integral part of the research. The students were encouraged to work with the community to find solutions together. Data gathering and an analysis were performed with the consent of the learning partner and community, because research of this nature could give rise to sensitive issues such as the "white gaze" (Fanon, 1967, p. 112) and the fascination with the poor, exotic (Fanon, 1967), which could hamper actual reflective learning.

Action research demands a certain amount of self-reflection where one can stand apart from the process of one's learning and aim to understand the process itself. Zuber-Skerrit (2001) refers to both action learning and action research taking place simultaneously. Action learning is "learning from action or concrete experience as well as taking action as a 
result of this learning" (Zuber-Skerrit, 2001, p. 2). As a theoretical framework for action research, Zuber-Skerrit (2001) uses a grounded theory (raw data and contextual knowledge), personal construct theory (where all participants become active constructors of knowledge), critical theory (where participants develop a self-critical and self-reflective attitude) and systems theory (where participants develop holistic resolutions to complex problems). Action research recognizes that human beings, communities or organisations are difficult to predict, and that their characteristics, ideas, strategies and behaviour are complex. The aim is not to produce generalisations, but to know, understand, improve or change a particular perception or social situation for the benefit of all the participants.

The psychoanalytic learning perspective of Fenwick (2001) was used as a framework for this study. It focuses on the inner struggle of the ego, negotiating between the inner and outer world. It opens up the area of the unconscious, which could cause repression or resistance inside individuals towards themselves, towards learning and towards the outside world. This tension could generate anxiety, which causes resistance. For learning to take place, people have to be "deliberate experimenters in their own learning and willingly engaging in traumas of the self" (Fenwick, 2001, p. 33). Learning is some personal experience where the inner and outer worlds constantly interact. Exploring your own mind or imagination is a fascinating process to enable better understanding of yourself, as well as interactions with others.

\section{Findings}

The aims of the Service-Learning module relate to Nussbaum's (2002) list of valuable abilities to promote mutual respect for opinions between all participants, to reflect on own traditions and on inherited or ingrained perceptions and stereotypes, to neutralize power relations between participants and to recognize valuable local and indigenous knowledge in a global world. The current Service-Learning module consists of research, community interactions, practical art projects, discussions and reflections. Interactions with communities are facilitated by a non-governmental organization that links each student with a person who is called a "learning partner".

\section{The role of artistic practice}

Dewey (1980) highlights the critical and social function of art and argues that the process of making art or creativity is found in all human actions. Human creativity is formed mostly in the subconscious. Creativity requires looking at many options and finding new combinations of options. Hofstadter (1985) talks about "slippability" (p. 237) or the capability of being unpredictable, making mistakes and identifying coincidence. The unpredictable is often the source of a creative thought. Niederhelman (1998) argues that design as a subject offers a "tool for creating connections between ideas, information, people and objects" (p. 84). Niederhelman (1998) also refers to Buchanan (1998), who 
argues that "we need to spend more time teaching non-designers design knowledge". Design could be a connecting link with many bodies of knowledge (Buchanan, 1998).

Art triggers the imagination, a process that involves participants more actively. Nielsen's (2006) study on imaginative teaching highlights several teaching methods, such as exploration, storytelling, discussion and empathy to encourage the imagination. Ilyenkov (2007) argues that the imagination refers not only to imagining that which does not exist, but also to seeing and recognising that which really exists. Ilyenkov (2007) refers to Goethe who wrote that the imagination is the basis of our interaction between people, but that the most difficult action is to "see with one's own eyes what lies before them" (p. 81). We are confined to our constructed social and personal categories and stereotypes. Without the imagination, according to Ilyenkov (2007), we see what we already know and not what is really there. It is necessary to examine and deconstruct critically that which we observe. The imagination is also necessary to imagine what we cannot see or experience. We could, for instance, imagine life through another person's eyes. The value of such an exercise could positively stimulate appreciation of cultural diversity.

The imagination keeps the mind active, stimulating creative and innovative thinking. The wonder of new knowledge is what keeps the artist continuing in their journey of discovering or combining to create novel ideas. The active participation in discovering new ideas is also important for motivation. Imaginative thinking relates to deep thinking. An active imagination also stimulates self-discovery and self-reflection. Shannon (1990) points to the value of art education to develop one's own identity. Buchanan (1989) encourages art and design students to present not only their successes, but also their problems because art and design are perfect vehicles for discovery and development of the self.

The pressure to produce new ideas requires critical analysis of one's social environment to enable the creation of new metaphors and analogies. Using metaphors or analogies is an indirect way of communication that involves the viewer in resolving the mystery of the message. Art that uses metaphors concretely involves participants both consciously and sub-consciously and serves to encourage the opening up of more possibilities for a diversity of interpretation. The gestalt concept of closure argues that when eighty percent of an image or concept is revealed, the viewers would complete the rest in their imagination and in that way be actively involved.

Theory and practice is integrated in praxis where praxis refers to learning by doing, reflection-in-action or reflective practice (Schön, 1987). Praxis in this module included creative practical activities, such as drawings, photo documentations and sound recordings. It also included explorations, such as mapping issues on the ground with coloured powder or leaves, drawing the problem in an abstract way and collecting objects related to the problem and creating collages. Collected data was, then, acted out, discussed or translated into visual imagery. The creative process of compiling data randomly and forcing new meanings by putting sensory and visual imagery together was a way of finding alternative or unexpected solutions, and this created new meanings. In that creative process of making variations of meanings, it was pointed out that there could be a variety of solutions, but all the variations could be valid. The process or product was then related back to issues such as diversity, power relations, colour divisions or whiteness/blackness. Projection exercises were also included as part of discussions and practical tasks, for instance, the students were 
asked to put themselves in the shoes of their learning partners and to make drawings of the person and combine it with a drawing of themselves. The students were more emotionally involved in their assignments because activities, such as drawing, acting and others, involve them physically and mentally. It resulted in an embodied experience, and learning involving both the body and the mind has the potential to be more effective.

An example of a project was where the elements and principles of art (line, space, shape, texture and size and balance, emphasis, unity and rhythm) were used and related to a social issue in the participants' own world. Line, for instance, related to racial or economic divisions, and space referred to the mental or physical space of society. The concepts (line, shape, etc.) were then acted out in a play. Drawings of the acts, a typographic collage or photos of the acts were then used to explain the concepts visually. Discussions and written reflections were included in the process. Sensitive issues were touched on, especially taking into consideration a colonial and recent apartheid past that is still visible in many aspects of everyday life in South Africa.

\section{The role of conversation and reflection}

A Socratic discussion style was followed in the conversations where questions were asked about a certain issue and various viewpoints were then discussed. The participants were divided in groups and argued from a certain viewpoint regardless of whether they agreed with that viewpoint or not. In such a way, one can imagine oneself in someone else's shoes. The space for these discussions was agreed on as a safe place, and participants could communicate freely. Because of the risk of uncontained emotions, a facilitator with experience of psychological therapy assisted the groups and facilitated further discussions of issues outside the group. The risk of perpetuating power relations, skewed perceptions was an aspect that one aimed to be aware of all the time. The baggage of the colonial and apartheid past is pre-existing and often taken as the norm.

Dewey (as cited in Bringle \& Hatcher, 1999) points out that a place of discomfort is the point where reflection starts. Structural reflection, in the form of writing or drawings, was used after each interaction and at the end of each project (Eyler, 2002). The AffectiveCognitive model (Smith-Tolken \& Du Plessis, 2009) that makes use of layered description of emotions or feelings related to critical thinking and theoretical frameworks and context was employed.

Kolb (1984) believes in integrating emotional experience with reflection, and explains that experience alone does not teach. A theory of transformative learning elaborated by Mezirow (1991) puts critical reflection at its core; it brings "assumptions, premises and criteria into consciousness" (p. 29). Fenwick (2001) puts the focus of experiential learning on reflection and argues that individuals construct their own meaning through reflecting on their interaction with their surroundings. Kayes (2002) describes the cognitive approach to learning as leading towards simplification, but the reflective approach to learning "leads towards complicatedness" (pp. 5-6). Schön (1987) describes two different types of reflections: reflection-in-action and reflection-on-action. For participants in the community 
interactions, there was space for reflection-in-action to take place. Schön's (1987) interest also lies in what the actual triggers are for reflection.

\section{Discussion and conclusions}

In this research, it became clear that art is, in fact, an effective medium to address sensitive issues as it makes use of indirect methods of communicating and interacting with the self. Art was also found to be an effective and expressive way to come to terms emotionally, in a non-confrontational manner, with the past and current realities in South Africa. What also emerged was that the art process on its own is not sufficient to fully address sensitive social responsibility and citizenship issues, but there were also external issues that influenced the effectiveness of the art process.

Working with such issues as racism and transformation is highly sensitive. Because of the strong emotions connected with the past, there were incidents of resistance that created barriers to learning. Some students were not motivated to participate, possibly because of fear of expressing their own emotions. It resulted in students being sick during the days when the community interactions took place and a general lack in enthusiasm during the rest of the project. In a module such as this one, it is difficult to judge the emotional state of a group; for some the conversations were confrontational and disruptive, but for others it was a challenge.

It is often assumed that the facilitator is emotionally mature enough to handle complex, sensitive issues in a class. There should be “... space for teachers to engage with painful personal legacies of the past” (Weldon, 2010, p. 353). Foucault (1986) highlights the 'care of the self' and argues that domination takes place when people do not care for themselves because they become slaves of their desires.

Other aspects that emerged were knowledge of hidden structures, discourses or oppression mechanisms in society different perspectives on what happened in history. There was a lack of relating theoretical readings and critical theory to everyday life; without linking these critical issues in one's mind the artistic process could become superficial. Accepting the fact that there are different interpretations of what happened in the colonial or apartheid past is important, and the process of listening to different interpretations of their artworks by classmates and relating that to history writing was an important process. Britzman (as cited in Kumashiro, 2000) remarks that "developing a critical consciousness involves not only learning about the processes of privileging/normalizing and marginalizing/Othering, but also unlearning what one had previously learned is 'normal' and normative" (pp. 36-37).

The imagination is necessary not only to imagine the unseen, but also to recognize what is really in front of one's eyes. Art education could be a useful tool to enable social responsibility and citizenship learning. Because it has the potential to enhance learning, art should therefore be accessible to more people. Further research and development of a future module that will be open to all students on campus to learn more about social responsibility and citizenship through the medium of art is suggested, with the guideline that this course is aimed at the development of a person's identity, not at becoming a future artist. 
People's confidence in the accepted norms of the apartheid past has been shattered because of inadequacies in social status and race. Psychological and self-confidence problems might be the single major obstruction to learning, apart from language barriers. A psychoanalytic learning perspective could be used to open up and reconcile some historical injustices in South Africa. Creating more space for participants to talk, write and artistically explore their personal experiences could be a means of coming to terms with emotions of the past and create a path for rethinking social responsibility and citizenship.

Reflecting on this module brings an awareness of the interesting nature of the entire process of research. The improved knowledge of social responsibility and citizenship and variations in students' perspectives and attitudes led to an enhanced understanding of how to accommodate multicultural students within the course curriculum.

\section{References:}

Beagan, B. L. (2000). Teaching medical students social responsibility: The right thing to do. Academic Medicine, 75(4), 346-350.

Bringle, R. G., \& Hatcher, J. A. (1999). Reflection in service-learning: Making meaning of experience. Educational Horizons, 77(4), 179-185.

Buchanan, R. (1998). Branzi's dilemma: Design in contemporary culture. Design Issues, 14(1), 3-20.

Department of Education. (1997). Education White Paper 3: A programme for the transformation of higher education. General Notice 1196 of 1997. Pretoria.

Dewey, J. (1980). Art as experience. New York: Berkley Publishing Group.

Eyler, J. (2002). Reflection: Linking service and learning - linking students and communities. Journal of Social Issues, 58, 517-534.

Fanon, F. (2006). The man of colour and the white woman. In A. Haddour (Ed.), The Fanon reader (pp. 46-58). London: Pluto.

Fenwick, T. (2001). Experiential learning: A theoretical critique from five perspectives information series. Retrieved May 5, 2006, from http://blackboard.liu.se/webapp s/portal/frameset.jsp?tab=courses\&url=/bin/common/course.pl?course_id=_1575_1

Foucault, M. (1986). Care of the self: Volume 3 of the history of sexuality. New York: Random House.

Haddour, A. (Ed.). (2006). The Fanon reader. London: Pluto.

Hofstadter D. R. (1985). Metamagical themas: Questing for the essence of mind and pattern. London: Penguin books.

Ilyenkov E.V. (2007). A contribution to a conversation about aesthetic education. Journal of Russian and East European Psychology, 45(4), 81-84.

Jansen, J. D. (2009). Knowledge in the blood: Confronting race and the apartheid past. Cape Town: UCT Press

Kayes, D. C. (2002). Experiential learning and its critics: Preserving the role of experience in management learning and education. Retrieved on May 15, 2006, from http://www.learningfromexperience.com/images/uploads/AMLE-electronic.pdf.

Kolb, D. A. (1984). Experiential learning. Englewood Cliffs, NJ: Prentice-Hall. 
Kumashiro, K. K. (2000). Towards a theory of anti-oppressive education. Review of Educational Research, 70(1), 25-53.

Mezirow, J. (1991). Transformative dimensions of adult learning. San Francisco: JosseyBass

Niederhelman, M. (2001). Education through design. Design Issues, 17(3), 83-87.

Nielsen, T.W. (2006). Towards a pedagogy of imagination: A phenomenological case study of holistic education. Journal Ethnography and Education, 1(2), 247-264.

Nussbaum, M. (2002). Education for citizenship in an era of global connection. Studies in Philosophy and Education, 21, 289-303.

Sankara, S., Dick, B., \& Passfield, R. (Eds.). (2001). Effective change management through action research and action learning: Concepts, perspectives, processes and applications. Lismore, Australia: Southern Cross University Press.

Schön, D. A. (1987). Educating the reflective practitioner. San Francisco: Jossey-Bass.

Shannon, J. M. (1990). Toward a rationale for public design education. Design Issues, 7(1, Educating the Designer), 29-41.

Smith-Tolken, A., \& Du Plessis, J. (2009). Effective learning through reflection in servicelearning. Paper presented at the $3^{\text {rd }}$ international conference on service-learning. University of Indianapolis, Indianapolis, USA.

Stellenbosch University, service-learning. (2011). Retrieved on January 19, 2011, from http://admin.sun.ac.za/gi/service\%20learning/centre.htm

Weinstein, J. R. (2004). Neutrality, pluralism and education: Civic education a learning about the other. Studies in Philosophy and Education, 23, 235-263.

Weldon, G. (2010). Post-conflict teacher development: Facing the past in South Africa. Journal of Moral Education, 39(3), 353-364.

Zuber-Skerritt, O. (2001). Action learning and action research: Paradigm, praxis and programs. In S. Sankara, B. Dick \& R. Passfield (Eds.), Effective change management through action research and action learning: Concepts, perspectives, processes and applications (pp. 1-20). Lismore, Australia: Southern Cross University Press.

\section{Correspondence:}

Elmarie Costandius, $\mathrm{PhD}$ candidate, MA in Education, MA in Fine Arts, Visual Communication Design, Visual Arts Department, Private Bag X1, Stellenbosch University, Matieland, 7602, South Africa. Email: elmarie@sun.ac.za 